\title{
Internal and External Forces in Typology: Evidence from Iranian Languages
}

\author{
Mohammad Dabir-Moghaddam
}

Allameh Tabataba'i University

\begin{abstract}
In this article the debate in the literature on the role of internal and external forces in shaping the typological features of a language is evaluated in the light of the evidence from Iranian languages. In this study the Greenbergian word order correlations as presented in Dryer (1992) are adopted as the theoretical and statistical framework. On that basis the common typological parameters of the languages studied are identified and the variations in them are also specified. Then the potential and actual areas of convergence/interference of these languages as substrata with Modern Persian as the superstratum are discussed. Despite instances of convergence/interference, the findings reveal the strength of the parameters of variation at the
\end{abstract}

\footnotetext{
* I would like to express my sincere thanks to Iran Scientific Research Council for providing me the grant for the research project 'Major Modern Languages and Dialects of Iran'(project number 4909). The present article is based on the corpus which was collected for the mentioned project. I am also grateful to Bernard Comrie for inviting me to Max Planck Institute for Evolutionary Anthropology (Leipzig) during July and August 2001, to pursue my research. I cherish great memories from the fascinating scientific environment at the institute.
} 
present time. However, the situation in regard to some of these languages is such that instances of even language shift in near future are not unexpected. Hence, it appears that in the Iranian languages studied the impacts of the internal and external forces in typology are potential and relativistic.

Keywords: word order, Iranian languages, internal forces, external forces

\section{Introduction}

In the literature on word order change scholars are divided into those who heavily rely on internal forces in accounting for word order changes, those who strongly advocate the role of external forces in explaining these changes, and yet those who are prepared to consider a scenario in which both internal and external forces play a role in the word order changes. Meillet (1914), Sapir (1921), Gerritsen (1984), and Lass $(1994,1997)$ represent the first group whereas Comrie (1981), Dryer (1992), Vennemann (1994), and Harris \& Campbell (1995) are representatives of the latter group, and Hickey (2002) may be cited as a supporter of the third position. In this article the word orders of Old Persian, Middle Persian, Modern Persian, and eleven Modern Iranian languages (spoken in different parts of Iran) are described and the variations in Modern Iranian languages are evaluated in the light of the debate on the role of internal and external forces in word order change. In the research to be reported, the Greenbergian word order correlations introduced in Dryer (1992) as well as in his unpublished data base (which is kindly made available to me) are adopted as the theoretical and statistical framework. In this study, I have specified the correlations which have remained stable in the Modern Iranian languages and those which reveal variation and diversity. The results are highly illuminative for the mentioned debate on the forces in typology. The 
majority of these Iranian languages clearly reflect very limited variations in the word order correlations. Two of the Modern Iranian languages form a minority in this respect in comparison to other Iranian languages. On the basis of the observations to be reported I will propose that the shared correlations are pan-Iranian and the variations are internal to the language(s). This seems to be the stateof-the-art in the word order typology of the Iranian languages described in the present study but the typological impact of Persian as a superstratum on present Iranian languages of Iran in the near future deserves particular attention. The impact seems to be a relativistic one. A large number of the substrata show very little variation in word order parameters with Persian so not much impact is foreseeable. Two of the Iranian languages which were referred to above as typological minorities reveal impacts from Persian in the parameters where the superstratum and the substrata are diverse. This interference/convergence is expected to be felt more strongly in the next two decades or so. If that happens, it will be a clear example of the role of language contact as an external force in syntactic borrowing. The strongest impact from the superstratum will be on a large number of Iranian languages which can be categorized as endangered languages. These are the languages spoken in towns and villages throughout the country. With the spread of public education and mass media bilingualism has become a norm in these places. To this should be added the general trend of migrations from villages. Hence, it appears that with these endangered languages one should expect a number of gradual language shifts - total substitution of Persian for the indigenous languages.

\section{The Greenbergian Word Order Correlations}

This article has relied on the spirit of the word order correlations which were initially discovered by Greenberg and were first 
presented in his (1963) article. These correlations were formulated in the form of implicational universals on the basis of a sample of thirty (and occasionally over thirty) languages. Dryer (1992) has pursued Greenberg's line of research and has reported the statistical results of his examination of the word order properties of 625 languages. Dryer (1992: 82) has provided the following definition for a correlation pair:

If the order of a pair of elements $\mathrm{X}$ and $\mathrm{Y}$ exhibits a correlation with the order of verb and object respectively, then I will refer to the ordered pair $\langle\mathrm{X}, \mathrm{Y}\rangle$ as a CORRELATION PAIR, and $\mathrm{I}$ will call $\mathrm{X}$ a VERB PATTERNER and $\mathrm{Y}$ an OBJECT PATTERNER with respect to this correlation pair. For example, since $\mathrm{OV}$ languages tend to be postpositional and VO languages prepositional, we can say that the ordered pair <adposition, NP> is a correlation pair, and that, with respect to this pair, adpositions are verb patterners and the $\mathrm{NP}_{\mathrm{s}}$ that they combine with are object patterners.

The specific correlation pair referred to in the above definition is substantiated by the statistics provided in the following table which is quoted from Dryer (1992: 83).

Table 1. Adposition Type

\begin{tabular}{|c|c|c|c|c|c|c|c|}
\hline & AFRICA & EURASIA & SEASIA\&OC & Aus-NEWGuI & NAMER & SAMER & TOTAL \\
\hline OV\&Postp & 15 & 26 & 5 & 17 & 25 & 19 & 107 \\
\hline OV\&Prep & 3 & 3 & 0 & 1 & 0 & 0 & 7 \\
\hline VO\&Postp & 4 & 1 & 0 & 0 & 3 & 4 & 12 \\
\hline VO\&Prep & 16 & 8 & 15 & 6 & 20 & 5 & 70 \\
\hline
\end{tabular}

In Table (1), the numbers indicate the number of genera containing languages of the given type in the given area. The large of the two numbers for each area and for each order of verb and object is 
enclosed in a box. Africa includes Semitic languages of southwest Asia; Eurasia=Europe and Asia, except for southeast Asia, as defined immediately; SEAsia\&Oc=Southeast Asia (Sino-Tibetan, Thai, and Mon-Khmer) and Oceania (Austronesian); Aus-NewGui= Australia and New Guinea, excluding Austronesian languages of New Guinea; NAmer=North America, including languages of Mexico, as well as Mayan and Aztecan languages in Central America; SAmer=South America, including languages in Central America except Mayan and Aztecan languages.

Dryer (1992) has discussed a number of correlation pairs of the kind exemplified in Table (1). I found nineteen of them applicable to the Iranian languages which are dealt with in the present research and a few remaining inapplicable. For instance, the pair 'order of plural word and noun' was excluded because the Iranian languages studied do not contain plural words. In these languages, plurality is expressed by a suffix. To the list of the correlation pairs described in Dryer (1992) I have added five more from his data base whose statistics were kindly made available to me by him. The complete list of the correlation pairs taken into consideration in this study are as follows:

1. Adposition type, 2. Order of noun and relative clause, 3. Order of noun and genitive, 4. Order of adjective and standard in comparative construction, 5. Order of verb and adpositional phrase, 6. Order of verb and manner adverb, 7. Order of copula and predicate, 8 . Order of 'want' and subordinate verb, 9. Order of noun and adjective, 10. Order of demonstrative and noun, 11. Order of intensifier and adjective, 12. Order of content verb and auxiliary verb, 13. Order of question particle and sentence, 14. Order of adverbial subordinator and clause, 15. Order of article and noun, 16. Order of verb and subject, 17. Order of numeral and noun, 18. Order of tense-aspect affix and verb stem, 19. Order of noun and possessive (not bound), 20. Order of verb and 
auxiliary verb 'able', 21 . Order of complementizer and sentence, 22. Not-obligatory-initial-wh or obligatory-initial-wh, 23. Order of object and verb, 24. Order of verb stem and negative affix.

\section{The Present Study}

In a preliminary study on the word order typology of Persian and selected Iranian languages (Dabir-Moghaddam 1997, 2001) I solely relied on Dryer (1992) and examined the word order behaviour of a number of Iranian languages. For instance, I used the correlation pair adposition type as specified in Table (1) and checked to see to what type Modern Persian fits best in its own area, i.e., EURASIA. As Modern Persian is predominantly a prepositional language, it contains the single postposition-rā which as I have argued elsewhere (Dabir-Moghaddam 1992) is a pragmatic-syntactic marker, I marked Persian as being compatible with the correlation pair OV \& Prep as well as with the correlation pair VO \& Prep. ${ }^{1}$ Since the former puts Persian in the minority group (i.e., as revealed in Table (1) 3 genera in EURASIA behave that way) whereas the second correlation pair puts Persian in the majority group (i.e., as shown in Table (1) 8 genera in EURASIA behave this way) I called Modern Persian a weak OV \& Prep and a strong VO \& Prep 'type' language. Similarly, I relied on the statistics in the last column of Table (1), which reveals the total number of genera globally, and concluded that Modern Persian is compatible with weak OV \& Prep and strong VO $\&$ Prep type languages (cf., 7 genera versus 70 genera). I, then, pursued the same comparison with respect to the other correlation pairs. For each pair, I was able to determine whether Modern Persian is compatible with a weak/strong OV type or a weak/strong VO type once in its own area and once globally.

\footnotetext{
${ }^{1}$ In this article the symbol $\bar{a}$ stands for the low back vowel.
} 
When I counted the results I realized that in about two third of the correlation pairs Modern Persian is compatible with strong VO type both in its own area and globally. This finding is particularly interesting because Modern Persian in terms of the linear order of its constituents is predominantly SOV both in its written and spoken varieties. To account for this disparity, in that preliminary study I raised the following hypothesis: "Persian is in the process of a syntactic change from an OV type to a VO type" (Dabir-Moghaddam 2001: 19).

In order to assess the above hypothesis, I relied on the same correlation pairs and examined the word order status of Old Persian, spoken between sixth to third centuries B.C., and Middle Persian, spoken until seventh century A.D. My examination of the Old Persian data revealed the following characteristics: (a) though there are many examples with the genitive+noun order the noun+genitive order is also permitted (Kent 1950: 309, 250) and (b) the word order in the sentence in Old Persian is quite free, but the normal order is subject-object-verb both in main and subordinate clauses; and subordinate clauses may stand either before or after the main clause (Kent 1950: 310). The Middle Persian data showed the following properties: (a) both noun+adjective order as well as adjective+noun order are attested (Heston 1976: 3), (b) similarly, both genitive+ noun and noun+genitive orders are observed (Heston 1976: 21-22), and (c) the most frequent word order is verb final order in transitive and intransitive sentences "although variant orders often occur" (Brunner 1977: 180). On the basis of these observations I proposed that Old Persian, which was incidentally an inflectional language, seems to have been basically a free word order language. Middle Persian was in consonant with Old Persian except that it was an analytic language. Modern Persian has become more configurational and analytic by fixing the noun+genitive order, the noun+adjective order, developing a large number of prepositions, and establishing an SOV constituent order in main and subordinate clauses when the 
object is phrasal and a very strong tendency to use the SVO constituent order when the object is clausal. Furthermore, I noted that $x$ āstan 'to want' and $d \bar{a}$ štan 'to have' are grammaticalized and used as future auxiliary and imperfective aspect auxiliary in Modern Persian and systematically precede the main verb. On the basis of these developments, I concluded that Modern Persian has drifted towards a VO type since Middle Persian period. I, then, conjectured that the findings partly support the aforementioned hypothesis, suggesting that Persian has been in the process of a syntactic change though not from a fixed OV type but from a free and flexible word order type in Old Persian towards a more configurational and VO type in Modern Persian (Dabir-Moghaddam 2001: 20-21).

In the present study, I have extended the previous study by (1) including the new correlation pairs introduced by Dryer, and (2) adding to my corpus a number of other Iranian languages spoken in Iran. I, then, relied on the analysis and description of my corpus to assess the debate on the role of internal and external forces in shaping the typological characteristics of languages. As I specified in the last paragraph of the previous section, the total number of the correlation parameters that I found relevant for Iranian languages are twenty four. I used those parameters to study the word order typology of the following Modern Iranian languages each spoken in a different part of the country:

- Gilaki (the Rasht dialect), a north-western Iranian language spoken in the province of Gilān (South west of the Caspian sea) in the north of Iran

- Māzandarāni (the Sāri dialect), a north-western Iranian language spoken in the province of Māzandarān in the north of Iran (south of the Caspian sea)

- Kurdish (the Sorāni dialect, dialect of Bāneh), a north-western Iranian language spoken in Kurdistān province in the westnorth of Iran 
- Howrāmi (the dialect of Pāweh), a north-western Iranian language spoken in Kermānshāh province, in the west of Iran

- Vafsi (the Vafs dialect), a north-western Iranian language spoken in the north-west of the Central province of Iran (the administrative center of this province is Arāk)

- Laki (the Kuhdasht dialect), an Iranian language spoken in the north and north-western regions of the Lorestān province in the west of Iran (south-east of Kermānshāh province)

- Lori (the Aznā dialect), a south-western Iranian language spoken in Lorestān province in the west of Iran

- Rāji (the Delijan dialect), an Iranian language spoken in Delijan region (north of the city of Isfahān) in the Central province of Iran

- Delvāri (the Tangsiri dialect), an Iranian language spoken in Bushehr province south of Iran in the Persian Gulf area

- Lāri (the Lār dialect), an Iranian language spoken in the Fārs province in the south of Iran

- Nāini (the Neyestānak dialect), a north-western Iranian language spoken in the Isfahān province in the center of Iran

The application of the twenty four word order parameters to Modern Persian as well as to the above mentioned Modern Iranian languages produced the results presented in Tables (2) and (3) below. Table (2) compares these languages with the number of genera spoken in EURASIA whereas Table (3) compares them with the number of genera globally. 
Internal and External Forces in Typology

Table 2. Modern Iranian Languages Compared with Genera in EURASIA

\begin{tabular}{|l|c|c|}
\hline \multicolumn{1}{|c|}{ Language } & OV Correlations & VO Correlations \\
\hline Modern Persian (MP) & 12 & 17 \\
Gilaki (G) & 16 & 15 \\
Māzandarāni (M) & 16 & 16 \\
Kurdish (K) & 12 & 18 \\
Howrāmi (H) & 13 & 17 \\
Vafsi (V) & 14 & 16 \\
Laki (LA) & 11 & 17 \\
Lori (LO) & 12 & 17 \\
Rāji (R) & 11 & 15 \\
Delvāri (D) & 12 & 16 \\
Lāri (LĀ) & 12 & 16 \\
Nāini (N) & 12 & 16 \\
\hline
\end{tabular}

Table 3. Modern Iranian Languages Compared with Genera Globally

\begin{tabular}{|l|c|c|}
\hline \multicolumn{1}{|c|}{ Language } & OV Correlations & VO Correlations \\
\hline Modern Persian (MP) & 15 & 19 \\
Gilaki (G) & 16 & 13 \\
Māzandarāni (M) & 16 & 14 \\
Kurdish (K) & 15 & 20 \\
Howrāmi (H) & 16 & 19 \\
Vafsi (V) & 16 & 18 \\
Laki (LA) & 14 & 19 \\
Lori (LO) & 15 & 19 \\
Rāji (R) & 14 & 17 \\
Delvāri (D) & 15 & 18 \\
Lāri (LĀ) & 15 & 18 \\
Nāini (N) & 15 & 18 \\
\hline
\end{tabular}

When I compared the individual word order parameters of the Modern Iranian languages studied I found the parameters listed in 
Table (4) common in them. The number enclosed to the right of each parameter refers to the number in the complete list of parameters at the end of the previous section in the present article.

Table 4. List of Common Parameters in Modern Iranian Languages

Order of noun and relative clause (2)

Order of verb and manner adverb (6)

Order of copula and predicate (7)

Order of 'want' and subordinate verb (8)

Order of demonstrative and noun (10)

Order of intensifier and adjective (11)

Order of question particle (if available) and sentence (13)

Order of adverbial subordinator and clause (14)

Order of article and noun (15)

Order of verb and subject (16)

Order of numeral and noun (17)

Order of tense-aspect affix and verb stem (18)

Order of verb and auxiliary verb 'able' (20)

Order of complementizer (if available) and sentence (21)

Not-Obligatory-initial-wh or obligatory-initial-wh (22)

Order of object and verb (23)

Order of verb stem and negative affix (24)

I call the parameters in Table (4) 'pan-Iranian parameters' as far as the Modern Iranian languages studied are concerned. Obviously, it is extremely interesting and informative to see whether or not the other Modern Iranian languages not included in this study, spoken in Iran and/or outside Iran, corroborate the findings reported.

The total number of the 'pan-Iranian parameters' in Table (4) are seventeen. That leaves only seven parameters, which I call 'parameters of variation'. The list of those parameters is provided in Table (5). 
Table 5. List of Variations in Modern Iranian Languages

Adposition type (1)
Order of noun and genitive (3)
Order of adjective and standard in comparative construction (4)
Order of verb and adpositional phrase (5)
Order of noun and adjective (9)
Order of content verb and auxiliary (12)
Order of noun and possessive (not bound) (19)

In Tables (6)-(12), each of the above parameters is specified in terms of the variations that the Modern Iranian languages reveal.

Table 6. Adposition Type

\begin{tabular}{|l|c|c|c|c|c|c|c|c|c|c|c|c|}
\cline { 2 - 11 } \multicolumn{1}{c|}{} & MP & G & M & K & H & V & LA & LO & R & D & LA & N \\
\hline Preposition & $\times$ & - & - & $\times$ & $\times$ & $\times$ & $\times$ & $\times$ & $\times$ & $\times$ & $\times$ & $\times$ \\
\hline Postposition & 1 & $\times$ & $\times$ & - & $\times$ & $\times$ & - & 1 & 1 & - & - & 2 \\
\hline Circumposition & - & - & - & 2 & - & - & - & - & - & - & - & 1 \\
\hline
\end{tabular}

Key: $x=$ several

$$
\text { - = absence }
$$

Table 7. Order of Noun and Genitive

\begin{tabular}{|l|c|c|c|c|c|c|c|c|c|c|c|c|}
\cline { 2 - 12 } \multicolumn{1}{c|}{} & MP & G & M & K & H & V & LA & LO & R & D & LA & N \\
\hline NG & + & - & - & + & + & - & + & + & + & + & + & + \\
\hline GN & - & + & + & - & - & + & - & - & - & - & - & - \\
\hline
\end{tabular}

Key: $+=$ presence

- = absence

Table 8. Order of Adjective and Standard in Comparative Construction

\begin{tabular}{|l|c|c|c|c|c|c|c|c|c|c|c|c|}
\cline { 2 - 11 } \multicolumn{1}{c|}{} & MP & G & M & K & H & V & LA & LO & R & D & LA & N \\
\hline Adj. + standard & + & - & - & + & + & + & + & + & + & + & + & + \\
\hline Standard + adj. & + & + & + & + & + & + & + & + & + & + & + & + \\
\hline
\end{tabular}

Key: $+=$ presence

- = absence 
Table 9. Order of Verb and Adpositional Phrase

\begin{tabular}{|l|c|c|c|c|c|c|c|c|c|c|c|c|}
\cline { 2 - 12 } \multicolumn{1}{c|}{} & MP & G & M & K & H & V & LA & LO & R & D & LA & N \\
\hline Adp. + V & + & + & + & + & + & + & + & + & + & + & + & + \\
\hline V + Adp. & - & - & - & + & + & \pm & + & - & - & - & - & - \\
\hline
\end{tabular}

Key: $+=$ presence

- = absence

$\pm=$ rare

Table 10. Order of Noun and Adjective

\begin{tabular}{|l|c|c|c|c|c|c|c|c|c|c|c|c|}
\cline { 2 - 13 } \multicolumn{1}{c|}{} & MP & G & M & K & H & V & LA & LO & R & D & LA & N \\
\hline $\mathrm{N}+$ Adj. & + & - & - & + & + & + & + & + & + & + & + & + \\
\hline Adj. + N & - & + & + & - & - & - & - & - & - & - & - & - \\
\hline
\end{tabular}

Key: $+=$ presence

$-=$ absence

Table 11. Order of Content Verb and Auxiliary

\begin{tabular}{|l|c|c|c|c|c|c|c|c|c|c|c|c|}
\cline { 2 - 12 } \multicolumn{1}{c|}{} & MP & G & M & K & H & V & LA & LO & R & D & LA & N \\
\hline Content verb+Aux. & + & + & + & + & + & + & - & + & + & + & + & + \\
\hline Aux.+content verb & + & + & + & + & + & + & + & + & + & + & - & + \\
\hline
\end{tabular}

Key: $+=$ presence

$$
\text { - = absence }
$$

Table 12. Order of Noun and Possessive (not Bound)

\begin{tabular}{|l|c|c|c|c|c|c|c|c|c|c|c|c|}
\cline { 2 - 12 } \multicolumn{1}{c|}{} & MP & G & M & K & H & V & LA & LO & R & D & LA & N \\
\hline N + Possessive & + & - & - & + & + & + & + & + & + & + & + & + \\
\hline Possessive + N & - & + & + & - & - & - & - & - & - & - & - & - \\
\hline
\end{tabular}

Key: $+=$ presence

$$
\text { - = absence }
$$

\section{Instances of Interference/Convergence}

The variations tabulated in Tables (6)-(12) represent the potential 
areas of interference/convergence. With the special stance of Modern Persian as the superstratum in Iran (since this language is the official language of the country, it is the language of education from kindergarten to university, and it is the language of the mass media) hence it is conceivable that the substrata will converge with Modern Persian in those parameters, which they reveal variation and diversity. The extent and speed of actual convergence is hard to predict since a multiplicity of external factors might be involved which can hasten or hinder the process (socio-cultural factors, geographical factors such as distance from Persian speaking centers or being a tourist resort, administrative factors such as being a provincial capital (which requires the use of the official language, etc.)). However, a few instances of interference/convergence are cited below.

Occasionally in my corpus of Māzandarāni, which is one of the two typological minorities within the Iranian languages described in the present study, I have noted the interference of a Persian preposition, e.g., be esfahān 'to Isfahān' for a construction in Māzandarāni, i.e., esfāhān/esfàhun, which is unmarked for any adposition. As Table (6) shows Māzandarāni is basically postpositional. In the same corpus, I have also witnessed the noun+adjective order typical of Modern Persian, e.g., mardi-y-e qadbelend 'Lit. man tall', instead of adjective+noun sequence which is common in that language (see Table (10) above). Also in Gilaki, the second typological minority among the languages I have studied, in one questionnaire I came across the substitution of the Persian preposition az 'from' for the expected postposition - $\mathrm{h}$ which I found in another questionnaire,

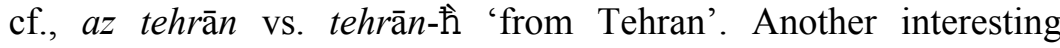
observation related to the issue of language contact and convergence is the use of the Kurdish definite marker - $a k a$ (or its variant $-a$ ) in one Lori dialect. My corpus of Lori consists of data from three dialects, only one of them that is Lori of Kangāvar which is spoken in the vicinity of Kurdish contains this definite marker, cf., Kurdish 
aw piyāw-a 'Lit. that Man-definite', Lori (Aznā) $u$ mard 'Lit. that man', Lori (Khorram Ābād) u PIyā 'Lit. that man', Lori (Kangāvar) $u$ mard-aka 'Lit. that man-definite'. In this case, we witness the convergence of the substratum Lori with Kurdish which is a local superstratum.

Despite the very existence of the mentioned instances of interference/convergence which are due to the role of a superstratum and hence congruent with the external factors' thesis, it is interesting to note that in some parameters of variation, e.g., adposition type shown in Table (6), we have not yet seen the expected impact from Persian.

To be more specific, the Modern Persian postposition -rā $(<$ Middle Persian $r \bar{a} d / r a \bar{a} y<$ Old Persian rādiy) was used in Early Modern Persian texts $\left(10^{\text {th }}-13^{\text {th }} \mathrm{C}\right.$. AD) as (a) a dative marker, e.g., Samarqand-rā čā $h \bar{a} r$ dar bud 'Lit. Samarqand-for four gate was', (b) an indirect object marker, e.g., Firuz-rā goft-and 'Lit. Firuz-to saidthey', and (c) a direct object marker, e.g., ferown kudakān-rā mikošt 'Lit. Pharaoh children-DO used to kill' (Lazard 1970: 383-384). In Modern Persian, however, this postposition is syntactically established as a direct object marker and is never used as a dative or indirect object marker, e.g., man ketāb-rā be ali dā d-am 'Lit. I bookDO to Ali gave-I'. It is interesting to note that the example cited under item (a) above about Early Modern Persian is reanalyzed in Modern Persian as Samarqand Čā $\bar{a} r$ dar dāšt 'Lit. Samarqand four gate had'. The example shows the reanalysis of the dative object as subject and the replacement of the verb dāštan 'to have' for budan 'to be' (see Dabir-Moghaddam 1992 for a diachronic and synchronic treatment of $-r \bar{a})$. On the other hand, we witness a whole range of variations in the use of this postposition in some of the Iranian languages described in the present study. For instance, in Vafsi this postposition is used to mark a dative and an instrumental object, e.g., $\overline{\mathrm{a}} n$ forušgā-da tāwān-rā $k \overline{\mathrm{a}} r$ arkare 'Lit. He shop-in we-for work does' and tamen bar kellay-rā taq-om niyā, 'Lit. I door key-with 
open-I did'. In Māzandarāni, it is used to mark both direct object and indirect object, e.g., men ketāb-re hedāme maryem-re 'Lit. I book-DO gave Maryam-IO'. In Nāini, it is used to mark dative object only, e.g., on tu doku mā-rā kār akira 'Lit. He in shop we-for work does'. And in Lāri, it is totally non-existent, e.g., ana mard-ü

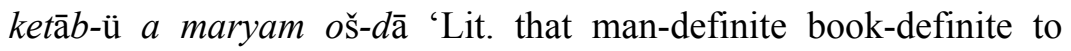
Maryam he-gave'. These observations reveal the strength of the inherent features of these languages. It remains to be seen whether or not this strength is going to be weakened in future due to contact with Modern Persian as the superstratum.

This is the state-of-the-art on potential and actual parameters of interference/convergence in Modern Iranian languages. It should be noted that although the languages referred to earlier are substrata in relation to Modern Persian, some of them are by no means endangered languages. More specifically, Māzandarāni, Gilaki, Kurdish, and Lori are spoken by hundreds of thousands of speakers. Endangered languages are those spoken in villages and small towns in different parts of the country. Speakers of these languages are bilingual and my informants have notified me that in some of those areas children tend to use Persian when they play together outside home. This situation combined with the wave of migrations to urban areas is linguistically quite alarming since it may lead to an extreme case of convergence, i.e., language shift-total substitution of Persian for an indigenous language.

\section{Conclusions and Implications}

In this article I dealt with the question of the role of internal and external forces in shaping the word order typology of a number of Iranian languages of Iran. As a preliminary step in addressing this question, I introduced the Greenbergian word order correlations and relied on twenty four parameters which are relevant for Iranian 
languages and showed that the majority of the twelve Modern Iranian languages studied in this article match with VO type both in their own geographical area, i.e., EURASIA, and globally (see Tables (2) and (3)). I, then, listed the common parameters in these languages which I called pan-Iranian features (see Table (4)) and also identified parameters of variation in them (see Table (5)). In Tables (6)-(12) the diversities in the Iranian languages on each of the parameters of variation were specified. In addition to the specification of the potential points of interference/convergence which are detectable from these last tables, a number of actual interferences/convergences were discussed as well. It was mentioned that a more alarming situation is the status of a number of endangered Iranian languages in Iran. In the case of these languages, the occurrence of language shift is not unexpected in the next two decades.

In the light of these observations and discussions I am inclined to suggest that the state-of-the-art in the Iranian languages studied favors the strong role of internal forces. Diachronically Old Persian drifted morphologically towards an analytic language in Middle Persian and Modern Persian, and Modern Persian became syntactically more configurational by fixing a number of flexible parameters in Old and Middle Persian. The Modern Iranian languages reveal a large number of pan-Iranian parameters and variations in a few other parameters. Instances of interference/convergence are not many as of now. The real test of threat will come in the near future when we theoretically expect convergences in some cases and language shifts in some other. If that happens, then we have to embrace the role of language contact and syntactic borrowing more seriously. Hence, it appears that the two forces are potential and relativistic. 


\section{References}

Brunner, C. 1977. A Syntax of Western Middle Iranian. Delmar \& New York: Caravan Books.

Comrie, B. 1989. Language Universals and Linguistic Typology. Chicago, IL: University of Chicago Press.

Dabir-Moghaddam, M. 1992. On the (In)dependence of Syntax and Pragmatics: Evidence from the Postposition-rā in Persian. In D. Stein (ed.), Cooperating with Written Texts: The Pragmatics and Comprehension of Written Texts 549-573. Berlin: Mouton de Gruyter. 1997. Descriptive and Theoretical Aspects of

Word Order Status in Persian and Selected Iranian Languages. In B. Caron (ed.), Proceedings of the $16^{\text {th }}$ International Congress of Linguists. London: Elsevier Science Ltd. . 2001. Word Order Typology of Iranian Languages.

The Journal of Humanities 2.8, 17-23.

Dryer, M. 1992. The Greenbergian Word Order Correlations. Language 68, 81-138.

Gerritsen, M. 1984. Divergent Word Order Developments in Germanic Languages: A Description and a Tentative Explanation. In J. Fisiak (ed.), Historical Syntax 107-136. Berlin: Mouton.

Greenberg, J. 1963. Some Universals of Grammar with Particular Reference to the Order of Meaningful Elements. In J. Greenberg (ed.), Universals of Language 73-113. Cambridge: MIT Press.

Harris, A. \& L. Campbell. 1995. Historical Syntax in Cross-linguistic Perspective. Cambridge: Cambridge University Press.

Haspelmath, M., E. König, W. Oesterreicher, \& W. Raible. (eds.). 2001. Language Typology and Language Universals 1. Berlin \& New York: Walter de Gruyter.

Heston, W. 1976. Selected Problems in Fifth to Tenth Century Iranian Syntax. Unpublished Ph.D. Dissertation. Philadelphia, PA: University of Pennsylvania.

Hickey, R. 2002. Internal and External Forces Again: Changes in Word 
Order in Old English and Old Irish. Language Sciences 24, 261-283.

Kent, R. 1950. Old Persian. New Haven, CT: American Oriental Society.

Lass, R. 1994. Old English: A Historical Linguistic Companion.

Cambridge: Cambridge University Press.

1997. Historical Linguistics and Language Change. Cambridge:

Cambridge University Press.

Lazard, G. 1970. Etude quantitative de l'evolution d'un morpheme: La postposition $r \bar{a}$ en Persan. In D. Cohen (ed.), Melanges Marcel Cohen 381-388. The Hague \& Paris: Mouton.

Meillet, A. 1914. Le problème de la parenté des langues. Scientia 15-35.

Sapir, E. 1921. Language. New York: Harcourt, Brace, and World.

Vennemann, T. 1994. Linguistic Reconstruction in the Context of European Prehistory. Transactions of the Philological Society 92.2, 215-284. 